\title{
Immortal Mentor Celebrates Y. Austin Chang's Personal and Professional Contributions
}

\section{Kelly Zappas}

\section{How to Order}

The English edition of Immortal Mentor is now available for purchase for $\$ 45$ plus shipping. To order your copy, please contact Jean Chang at pjhchang@gmail.com with your name and shipping address. Personal check and cashier's check are accepted.

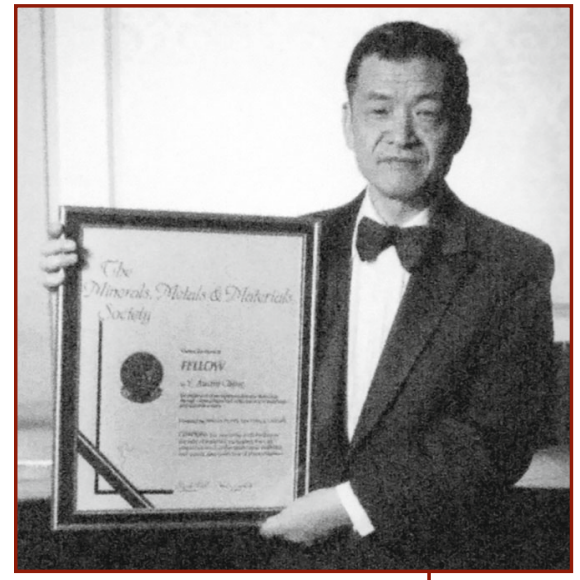

An extraordinary scholar. An internationally renowned material scientist. An immortal mentor. This is how some of Y. Austin Chang's colleagues describe him in their introductions to the new book Immortal Mentor: A Warm and Inspiring Biography of Y. Austin Chang. Published and edited by his wife, P. Jean Chang, this personal biography looks beyond Chang's professional accomplishments to tell a more complete story of his life, from his early years as a boy in China to his education in the United States and the legacy he left behind.

Austin Chang was a figure familiar to many TMS members. He was named a fellow of the Society in 1991 and served as the 2000 TMS President. He is widely regarded as a leading scholar in the field of solid-state solution thermodynamics and its applications to the analysis of phase equilibria and defect energetics in solids. Based

Y. Austin Chang accepts his TMS Fellow award in 1991.

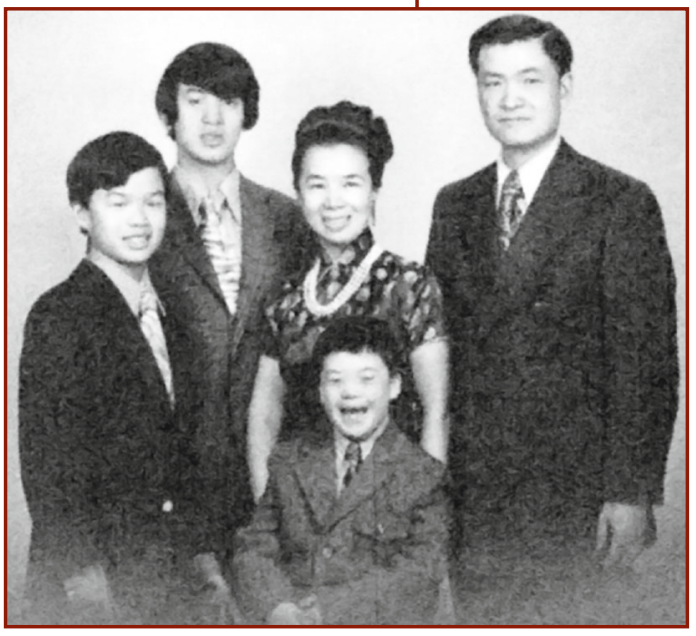

This family portrait shows Chang with his wife and three sons. Back row, from left to right: Larry, Vincent, Jean, Austin, and, in front, Theodore Chang. on the groundbreaking codes that he developed, Chang founded CompuTherm LLC, which produces user-friendly computer software and databases for thermodynamic calculations. He passed away in August 2011 at the age of 78 .

Written in friendly, accessible language, Immortal Mentor is divided into five sections that examine various aspects of Chang's life: his childhood, marriage and family life, his professional achievements, the inspiration he provided to others, and his retirement and later years. In extensive appendices, the book also includes a collection of tributes written by Chang's friends and colleagues, along with a listing of his many accomplishments.

Immortal Mentor is an English translation of the Chinese book, $A$ Person Having Stories-Academician Yong-Shan Chang, published in 2016 by National Tsing Hua University, Taiwan.

Jean Chang wanted to have the book translated so that her sons, as well as Austin Chang's many friends and colleagues in the United States, would have the chance to read her husband's story.

"He was a very private person," said Jean. "People didn't know much about his personal life."

She described the story of Chang's life as a success story, pointing out that he had no formal education in math or science until the age of 13 , but went on to a distinguished career. By the end of his life, he had been elected to such prestigious organizations as the U.S. National Academy of Engineering, the Chinese Academy of Sciences (as a foreign member), and, the year before his death, the Academia Sinica in Taiwan.

Austin Chang never told people what to do, his wife said, but instead tried to set a good example. Now the example that he set with his life is preserved in the pages of this book.

Editor's Note: Photos in this article are reprinted with permission for use from P. Jean Chang.

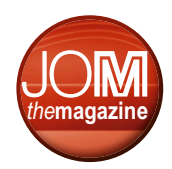

